\title{
Recursos de poder sindicales y relaciones de clase. Elementos para una mirada de largo plazo de Argentina y México
}

\author{
Union power resources and class relations. Elements for a long-term view of Argentina and Mexico \\ Agustin Santella \\ CONICET, Instituto de Investigaciones "Gino Germani”, Universidad de Buenos Aires, Argentina \\ agustinsantella@gmail.com \\ Iván Montes de Oca \\ Instituto de Investigaciones "Gino Germani”, Universidad de Buenos Aires, Argentina \\ ivanfmontedeoca@gmail.com
}

\begin{abstract}
Resumen:
El neoliberalismo ha intentado desmovilizar a la clase trabajadora a nivel global. El objetivo de este texto es contribuir a entender estos cambios en Argentina y México. La desmovilización de los trabajadores ha afectado diferencialmente a ambos países debido a factores estructurales y políticos de largo y mediano plazo. Nuestro argumento es que la desmovilización sindical ha afectado más a los trabajadores y trabajadoras mexicanas debido a la presencia de una sobrepoblación relativa de tipo rural, ausente en la Argentina, diferencia que es expresión de historias de formación capitalista distintas. Estas historias albergan formaciones hegemónicas del Estado que mantienen una continuidad institucional en México, mientras que en Argentina manifiestan crisis hegemónicas recurrentes
\end{abstract}

Palabras Clave: Movilización obrera, Neoliberalismo, Recursos de poder, Argentina, México.

\section{Abstract:}

The neoliberal changes have intended to demobilize working class word widely. The aim of this paper is to contribute to understanding these changes in Argentina and Mexico. The demobilization of the working class has affected both countries in different ways because of long and medium-term political and structural factors. It is argued that workers demobilization has affected more to Mexican workers because of the presence of a rural surplus relative population, absent in Argentina, which is the expression of a different history of capitalist formation. These histories imply a different hegemonic state formation, where an institutional continuity in Mexico is observed, instead of a recurrent hegemonic crisis in Argentina

KeYWORDS: Workers mobilization, Neoliberalism, Power resources, Argentina, Mexico.

\section{INTRODUCCIÓN}

Los cambios sociales en el período del neoliberalismo han apuntado, entre otras metas, a la desmovilización de la clase trabajadora a nivel global. No obstante, el impacto de estos cambios ha sido muy desigual en el mundo. El objetivo de este texto es aportar a la construcción de las observaciones sobre estos cambios, así como de su explicación histórica. Los casos de Argentina y México tienen características comunes y diferentes. Desde los años 1970-1980 ambos han experimentado cambios y políticas neoliberales que han afectado a sus movimientos obreros e intereses colectivos. No obstante, los procesos, formas y características de estos han diferido notablemente. Esto se debería a la inserción de los cambios en procesos de largo plazo, y las realidades de sus formaciones económicas y políticas en las que aquellos se insertan. Hay en las investigaciones especializadas recientes cierto consenso respecto a que los impactos del neoliberalismo 
han sido más desmovilizadores en el movimiento obrero mexicano (Bensusán, 2016; Cook, 2007; Bensusán y Cook 2015; Zepeda Martínez, 2009).

En este texto nos proponemos realizar una exploración para la comparación internacional de las relaciones de fuerza entre los empresarios, estados y trabajadores. Nuestra pregunta general es la siguiente: ¿De qué modo podemos dar cuenta del poder de negociación y la fuerza relativa de los trabajadores? ¿De qué depende y cuál es el proceso de su formación? Intentaremos brindar algunos elementos a través del uso de conceptos, dialogando con las investigaciones sobre los "recursos de poder". Sobre la base de teorías iniciales, este texto refleja un estado de investigación que consiste en la búsqueda de observaciones que permitan sostener los mecanismos presupuestos o sugeridos teóricamente. Elegimos los casos argentino y mexicano porque nos permiten ilustrar la contraposición de tendencias nacionales en el mismo período neoliberal o, dicho de otro modo, que las tendencias de la globalización no son uniformes. Por otro lado, estos países representan dos de las principales economías políticas de América Latina con fuertes sistemas de relaciones laborales.

A continuación de esta introducción (1), este artículo expondrá el (2) marco conceptual donde se incorporan los problemas de este estudio desde las categorías de recursos de poder. Luego (3) haremos una introducción histórica secular comparativa de los procesos de proletarización y acumulación de capital en México y Argentina. Desde nuestro punto de vista, la literatura especializada no ha dado cuenta suficientemente de este tipo de legados estructurales. En cuarto lugar (4), describimos sintéticamente diferencias en los mercados de trabajo que expresan el modo en que los legados estructurales se actualizan en el período del neoliberalismo (1980-presente). En el quinto apartado (5) comparamos la trayectoria de los regímenes que afectan las relaciones de poder institucionales entre trabajadores y empresarios, retomando los legados institucionales que condicionan la movilización de las clases trabajadores. En el siguiente apartado (6) damos cuenta, finalmente, de las diferencias en los indicadores de movilización de los trabajadores en ambos países en el período del neoliberalismo (desde 1980). Por tanto, en este ensayo combinamos la temporalidad de largo plazo, en tanto legados del pasado que condicionan el presente, con la de mediano plazo, cuando comparamos los casos en el período neoliberal. Esta comparación en ambos niveles temporales nos permite confrontar una paradoja en las trayectorias que desafía a las prognosis de la desaparición del movimiento obrero como resultado de la desindustrialización. Durante el neoliberalismo en México se experimenta un marcado declive de la movilización sindical a pesar de un proceso de nueva industrialización. En contraste, donde la desindustrialización ha sido mucho más marcada, en Argentina, el movimiento obrero ha mantenido una considerable posición de fuerza.

\section{MARCo CONCEPTUAL}

El Global LabourJournal ha publicado en 2018 un dossier sobre el enfoque de recursos de poder (powerresourcesapproach) que, con diferentes presentaciones, intenta dar cuenta del poder relativo de los trabajadores. "Uno de los objetivos del enfoque de recursos de poder es destacar la posibilidad de la agencia de los trabajadores cuando la narrativa dominante sigue siendo la de la declinación del sindicalismo debido al proceso de globalización" (Schmalz, Ludwig y Webster, 2019, p. 86). Como introducción del mismo, Schmalz et al. $(2018,2019)$ construyen una síntesis crítica que distingue cuatro tipos de recursos: estructural, asociativo, institucional y societal. Los dos primeros vienen de Wright (2000) y Silver, dos autores clave del enfoque. ${ }^{1}$ El poder estructural trata de la relación de poder entre capitalistas y trabajadores en los mercados de trabajo, en el lugar de trabajo o en la estructura económica. Una economía donde se ha extendido la relación asalariada presenta un proletariado extenso, que es el primer aspecto en la relación de fuerzas. Un mercado de trabajo con baja desocupación fortalece, a su vez, la posición de negociación de los trabajadores en el curso de los conflictos. Las relaciones estructurales permean distintas formas en el espacio y tiempo económico. Los autores mencionan la logística de la producción configurada dentro del ciclo del capital. Así, los empleados de transporte negocian como poder su capacidad de interrumpir la circulación de personas y mercancías; y 
así, determinados grupos de trabajadores pueden usar su "poder logístico" cuando ocupan posiciones clave en la economía de exportación (puertos o aeropuertos) (, p. 124). ${ }^{2}$ Pero también "el poder logístico puede por ejemplo movilizarse por los cortes de calle por otros grupos sociales que no son asalariados, como los trabajadores informales por cuenta propia" (Schmalz et al., 2018, p. 117).

Sin embargo, para realizar este poder los trabajadores deben asociarse. "El poder asociativo es la capacidad de los trabajadores de movilizarse para actuar colectivamente" (Schmalz et al., 2019, p. 84). Este poder se observa en la organización sindical o política de la clase trabajadora (sindicatos y partidos). El poder institucional se refiere a la negociación en las instituciones políticas, lo que puede expresarse en las leyes y normas, aunque también la práctica institucional como tal (la represión ilegal, por ejemplo). El poder societal (quizá el término menos evidente) se refiere, para Schmalz et al., a las alianzas con otros actores sociales, pero también a la producción discursiva e identitaria que formará un recurso de poder de los trabajadores, especialmente en grupos obreros con menos poder estructural o político.

La comprensión subjetiva de la situación y la misma acción es un componente fundamental para la movilización. Un modo de indicar las identidades es a través de los repertorios discursivos, los cuales pueden entenderse como formas dialogales que se construyen en el curso de las luchas entre los actores. Estos discursos de lucha pueden seguir a través del análisis de los lenguajes desplegados en esos contextos específicos. Desde esta perspectiva, las identidades hacen a la "producción de significado como una acción colectiva esencialmente conflictiva que es motivada por el conflicto de grupo y la misma dinámica interna del discurso" (Steinberg, 1999, p. 737). En particular, los estudios de la "economía moral" han propuesto un enfoque útil al sostener que las movilizaciones populares se han dado cuando en la percepción de que las clases dominantes han roto las normas históricamente aceptadas de justicia. Esta economía moral se constituye en una "fuerza moral" que sostiene la acción colectiva.

El argumento de este artículo es que las movilizaciones de trabajadores en Argentina y México diferirán debido tanto a la historia económica de sus formaciones sociales como a las tradiciones de las identidades populares que se formaron a través de los repertorios de lucha. Las formas de lucha elegidas por las clases subalternas son modos aprendidos históricamente a lo largo de la experiencia. Debido a su experiencia, en México los sectores en vías de proletarización construyeron un repertorio campesino e indígena tanto para sus formas de acción como para su presentación como sujetos, así como en Argentina predominaron los repertorios del movimiento obrero. Así, lo indígena, campesino o trabajador designan tanto una posición estructural como una identidad subjetiva. Desde esta perspectiva, los estudios de casos en profundidad deben seguir estas identidades mediante el estudio de los lenguajes desplegados en las luchas. Por carácter sintético de este artículo, presuponemos teóricamente el registro del discurso como un componente de la acción colectiva en distintos momentos del análisis. Así, adelantando el argumento del apartado 3, el proceso de proletarización temprana en México en 1900 fue contestado por los campesinos sobre la base de la identidad construida en su economía moral secular, producto a su vez de las luchas del siglo XIX. La resistencia campesina será un factor fundamental en el desarrollo social y político mexicano que forma parte de los legados estructurales e institucionales que expondremos más abajo.

La síntesis de Schmalz et al. reúne las dimensiones del poder usualmente no articuladas en los estudios previos. Los especialistas en luchas de clases, acción colectiva y movimientos sociales se han dividido por largo tiempo al estudiar los aspectos estructural- económico, estratégico asociativos e institucionales o identitarios. Al dar cuenta de las diferencias en el poder de movilización, en este artículo se intentará integrar dinámicamente estas dimensiones. Collier y Collier (1991) y Bensusán (2016) han estimado las diferencias en el poder de los movimientos obreros latinoamericanos en el período de formación y el contemporáneo respectivamente. No obstante, sus observaciones se han centrado en los poderes asociacional e institucionales. Esto puede verse en Bensusán y Cook (2015) para quienes las divergencias de las trayectorias del sindicalismo en Argentina y México se deben a los "legados del corporativismo estatal". Una interacción histórica con 
el poder societal (alianzas e identidad) ha sido ensayada para explicar el curso de los movimientos obreros nacionales (chileno, argentino y venezolano) por Bergquist (1988).

En la narrativa que expondremos más abajo buscaremos ver las relaciones entre las dimensiones. En particular, ampliaremos las formas estructurales teniendo en cuenta la presencia significativa del sector informal como un rasgo destacado de las economías en vías de desarrollo en el capitalismo dependiente latinoamericano. La historia de las formas de la "sobrepoblación relativa” en México y Argentina brindará, en nuestra perspectiva, una clave comparativa para dar cuenta de los distintos balances de poder sindical. Diversos estudios han asimilado las categorías de sectores informales y sobrepoblación relativa (Denning, 2011; Bhattacharya y Sanyal 2009), y también contamos con estimaciones empíricas de su peso en Nielson y Stubbs (2011) y Donaire (2018). ${ }^{3}$

\section{Legados estructurales en MéXico y Argentina}

Los indicadores más usados de proletarización son la urbanización y el empleo industrial (por ejemplo, Collier y Collier, 1991). Sin embargo, la proletarización puede de hecho comenzar en el sector agrario, como de hecho sugieren investigadores de los orígenes del capitalismo (Tilly, 1979, Mikkelsen, 1996). Aunque en México la población urbana era reducida en 1910, para entonces la mayoría de los pobladores agrarios habían sido semiproletarizados (Knight, 1992). Sobre esta base se ha interpretado a la revolución mexicana de 1911-1920 como una movilización armada del campesinado, expropiado, en lucha por la tierra. En contraste, en Argentina la mayoría del trabajo rural era realizado por obreros agrícolas asalariados. La rebelión de estos comenzaría hacia los años 1920, prologándose en la década de 1930, en forma de huelgas, producto de una reducción del salario real, relativamente alto en términos internacionales. ${ }^{4}$ Las luchas aquí se dirigieron hacia la recuperación del salario y/o condiciones de trabajo. También hemos de mencionar las luchas de los arrendatarios (Grito de Alcorta en 1912).

Los procesos históricos y las estructuras agrarias diferían considerablemente y con ello las experiencias y economías morales. En México los trabajadores rurales combinaban como ingresos los salarios y el uso de tierra a cambio de trabajo. Pero además pertenecían a comunidades que resistían la expropiación secularmente (Reina, 1998). En Argentina los trabajadores eran inmigrantes (en la región central del país), aunque posteriormente nacidos en el país, llegando ya despojados de la propiedad individual o colectiva. Aunque el proyecto de movilización de la fuerza de trabajo rural por parte del Estado argentino se hizo bajo la promesa de la colonización, se comprobó que esta era irreal. Antes bien, el objetivo de esta campaña fue superar el problema de la falta de mano de obra, creando la oferta necesaria, lo cual se lograría ya en 1900 (Adelman, 1992).

El grado de "apertura" al mercado internacional variaba enormemente si comparamos los dos países, a juzgar por la relación entre sector externo sobre el producto bruto. La economía monetaria estuvo poco desarrollada en México durante largo tiempo (Knight, 1992). El modo de inserción capitalista en el mercado mundial tendrá implicaciones en diversos aspectos clave. Esto se relaciona con la forma de la proletarización y la creación del mercado de trabajo asalariado;pero también podrá tener implicaciones en las demás dimensiones del poder estructural estratégico de negociación, si tenemos en cuenta que no existe una dependencia capitalista de la exportación en México como la hubo en Argentina en la cadena producción primaria-transporte. La aparición de las huelgas generales en la Argentina (la primera en 1902) recaería en el aprovechamiento de la "interconexión del proceso de trabajo e interdependencia" (Burawoy) a lo largo de la economía exportadora del campo a la ciudad y el transporte internacional. La posición estratégica de grupos de trabajadores aquí remite a la interconexión propia de la dependencia de distintas ramas en la economía de exportación: del transporte de la cosecha y en los momentos de su venta (ciclo económico de corto plazo) (Pianetto, 1984, p. 304). En México esta forma de lucha es prácticamente ausente. 
Como resultado de la movilización campesina en México, primero durante el proceso revolucionario 1910-1920, luego apoyada desde el Estado en el período 1936-1940, una parte de la estructura agraria se colectivizó en forma de ejidos. Hacia los años 1970 esta forma de propiedad se encontraba en una situación crónica de crisis de productividad, debido a la competencia del creciente sector capitalista rural (Bartra, 1985; Guzmán Ferrer, 1975). Desde 1960, se produce en México un desplazamiento de población y fuerza de trabajo desde la producción agraria hacia la industria y los servicios. Si bien se ha señalado la incapacidad de absorción de mano de obra de la industria, el crecimiento ha sido notable durante las décadas recientes. La población activa en el campo ha disminuido la mitad entre 1970 y la actualidad, siendo todavía sobresaliente, pero esto implica el desplazamiento del trabajo hacia el sector urbano. Uno de los argumentos refiere a la baja calificación de la mano de obra como obstáculo para su empleo. Sin embargo, el crecimiento industrial (maquilador), desde 1980, se ha sostenido sobre este bajo nivel de calificación.

\section{LOS MERCADOS DE TRABAJO EN MÉXICO Y ARGENTINA DESDE 1980}

Estos elementos contribuyen a presentar un proceso en el que se proletariza una parte de la población, pero sobre la base de una baja calificación y la presión constante de una sobreoferta de trabajadores, que contribuye a mantener bajos estos salarios. $\mathrm{Al}$ mismo tiempo, se mantiene un grupo no menor en el sector informal urbano. Habría así coexistido el empleo "informal" junto con el ingreso de fuerza de trabajo industrial desde los sectores rurales e informales. Diversos estudios observan la circulación de trabajadores entre ambos sectores, y no la separación estricta del sector industrial y la masa marginal. ${ }^{5}$ La demanda de empleados en la nueva industria maquiladora no sería suficiente para "dar trabajo" a los desplazados rurales, pero esto podría darse sin que medie un límite en la calificación requerida sino por la cantidad de trabajo. Dados los bajos salarios ofrecidos, y la posibilidad de alternativas de empleo en el sector informal, esta mayor oferta de trabajadores no redunda en el desempleo abierto, pero al mismo tiempo opera como ejército industrial de reserva.

El fenómeno de la rotación de personal en la maquiladora es un indicador significativo con relación a este problema. Desde su primera etapa, se ha manifestado una alta rotación de personal, como un fenómeno asociado al trabajo en las maquilas mexicanas (que han oscilado entre el 150\% y 60\% anual). La desocupación en las regiones empleadoras es menor, y estas experimentan mayor crecimiento demográfico debido a migraciones internas. A su vez, los salarios reales de la maquila decrecieron desde los años 1980 (aunque con leve crecimiento actual). Esto manifiesta una reserva de trabajo que rota entre empresas y/o sectores, con salarios muy bajos, sobre la base de una demanda constante y creciente de trabajo que implica la incorporación de nuevas obreras y obreros. ${ }^{6}$ A pesar de las transformaciones en otro sentido, el crecimiento del empleo industrial en México, un hecho que contrasta notablemente con Argentina, se sigue basando en los bajos salarios comparativos.

Algunos autores han señalado que el modelo clásico de la proletarización, producto de la emigración rural, no se evidencia en el caso de las maquiladoras (IME, por sus siglas, Industria Maquiladora de Exportación). Se señala como apoyo la baja participación de la migración rural en los trabajadores de la IME (Fernández-Kelly, 1983; Trevizo, 2011, pp.99-100). No obstante, un estudio más reciente afirma que los salarios de las maquilas se regulan por los mercados regionales de trabajo, esto es, por la relación con los salarios no maquiladores (Carrillo, 2014; Díaz González, 2009). Esto implica la existencia de una reserva creciente de trabajo que configura un mercado de trabajo. La trayectoria de expulsión de la fuerza de trabajo rural parece seguir un camino bifurcado, no directo hacia la maquila. No obstante, por un lado, el mercado de trabajo maquilador se sitúa en este contexto del cual se beneficia; por otro lado, diversos estudios sugieren que, dependiendo de la fase y región de establecimiento de las IME, ha cambiado el tipo de fuerza de trabajo que ingresa, en cuanto a las características sociales y demográficas de este grupo. ${ }^{7}$ 
Desde el punto de vista de la movilidad del capital industrial, se presenta un escenario distinto en el comienzo de los cambios neoliberales en ambos países. México será territorio de la movilidad de capital en búsqueda de espacios de mayor rentabilidad para superar las crisis de los años 1970, mientras que en Argentina incluso se observará lo contrario. Por ejemplo, las inversiones automotrices de las casas centrales se trasladaron desde Argentina a Brasil, u otros puntos, mientras que México ha sido y sigue siendo un país receptor. La industrialización liviana en México contribuyó a un cambio drástico en su estructura económica y la composición del sector externo, la cual pasará a conformarse de exportaciones industriales, provistas por las IME, cuando antes eran de bienes primarios. En contraste, en Argentina se experimentó una pronunciada caída del empleo industrial, denominada por ello mismo desindustrialización. Asimismo, esta economía no cambió la composición primaria de los bienes exportados aunque hayan cambiado los productos, reemplazándose las tradicionales carne y trigo, por soja y derivados como aceites.

Aunque la sobrepoblación relativa rural en México se ha ido disgregando, siendo parte del proceso de mercantilización de la tierra, aún es parte significativa de la informalidad. En Argentina la expulsión de trabajadores de la industria engrosó desde los 1970 el grupo de los trabajadores por cuenta propia, pero también configuró un nuevo umbral de desocupación y subocupación, el cual creció dramáticamente en la crisis de los años 1998-2002, así como el sector informal. Hacia 2010, en México la sobrepoblación relativa rural explica un 32\% de la sobrepoblación total, mientras que lo hace en un 5\% en Argentina. Todavía en México el 22\% de la población es rural, contra el 8\% en Argentina (Donaire, 2018). El indicador construido por Donaire para observar la sobrepoblación relativa en el campo es el de pobreza, asumiendo que podría dar cuenta de trabajadores del campo que no llegan con su ingreso o salario a cubrir las necesidades de consumo.

Las tasas de desocupación en México son significativa y continuamente bajas, si las comparamos con Argentina. Sin embargo, el mercado de trabajo mexicano tiene una composición distinta respecto de los modos de sobrepoblación. Frenkel y Ros (2004) sostienen que, a diferencia de Argentina, el sector informal en México absorbe las pérdidas de empleo producto de las políticas neoliberales. Estos datos vienen a señalar la ineficacia real de las instituciones formales reguladoras del mercado de trabajo.

La literatura comparativa sobre los mercados laborales sugiere la presencia de una tasa de rotación relativamente alta en México (más alta que en la Argentina), que parece indicar grandes flujos de empleo hacia adentro y hacia afuera del sector informal. Este grado de flexibilidad del empleo es consistente con una alta capacidad del sector informal mexicano para absorber las pérdidas de empleo de los sectores formales de la economía (p. 50).

En el mismo sentido Rosati (2015) se refiere a la Argentina y Brasil (1980-2009)

\section{PODER INSTITUCIONAL Y REGÍMENES HEGEMÓNICOS EN PERSPECTIVA HISTÓRICA}

La estabilidad del régimen político de la "revolución institucional" en México, hasta fines de los años 90, es uno de los aspectos más contrastantes con la inestabilidad política de Argentina (Knight, 1992). La institucionalización en México incorporó a los sectores populares, obrero y campesino fundamentalmente, en un marco tanto de concesiones a demandas como de control sobre sus aparatos organizativos. La estabilidad de largo plazo, por tanto, se relaciona con el control institucional de la movilización popular. Diversos autores plantean la construcción del régimen hegemónico en México por vía de las formas de movilización política e ideológica derivadas de la revolución mexicana. El régimen "revolucionario" habría entonces movilizado al campesinado mediante la reforma agraria. Gilly (1997) interpreta la integración de las luchas populares en el nuevo régimen político, como un modo de "mediación” y “constitución” del Estado.8 Hacia los años 1970 se abrieron espacios críticos vía una ola de protestas de los movimientos estudiantiles, campesinos y de pobres, así como de sectores obreros (Trevizo, 2011), aunque sin poner fin a este sistema de mediación. 
Con la apertura del neoliberalismo, se han socavado las bases materiales e ideológicas del modo hegemónico, abriendo espacio para diversas luchas sociales. ${ }^{9}$ Sin embargo, el movimiento sindical permaneció relativamente inmovilizado, luego de amenazas de choques entre las centrales y el gobierno en 1982 (Middlebrook, 1989). La conflictividad sindical se expresaría en algunos sectores rebeldes, como los maestros, y en movimientos campesinos e indígenas. Como señala el análisis del apoyo popular al PRD en la contienda electoral de 1988, quienes se movilizaron fueron campesinos y pobres, más que los obreros (Gilly, 1997). Foweraker y Landman (1997) realizan un estudio comparado de la movilización social en México y Brasil (también en Chile y España) entre 1964 y 1990. Aquí muestran el mayor protagonismo de los campesinos y movimientos de pobres urbanos en México, en contraste con la movilización de trabajadores en Brasil, país mencionado en su comparación por Foweraker y Landman. Medida por la cantidad de huelgas y particularmente el volumen de las huelgas (cantidad de huelguistas), la actividad de protesta obrera en México es significativamente baja, frente a la impetuosa ola huelguística argentina.

En Argentina observamos la discontinuidad en el régimen político institucional, sobre todo, el modo en que las organizaciones del Estado expresan las relaciones de fuerza sociales. El peronismo estuvo bajo disputa, expulsados del gobierno violentamente por las élites dominantes en 1955, temerosas de su autonomía política e incluso de la movilización de las clases subalternas que el populismo conllevaba. Esto se repitió en 1976 a Isabel Martínez de Perón. El movimiento sindical fue quien autónomamente dio continuidad al peronismo mientras fuera excluido del sistema político entre el segundo (1955) y tercer gobierno (1976), y posteriormente bajo la dictadura militar última.

La discontinuidad en los regímenes políticos sudamericanos expresaría la débil hegemonía de un bloque de poder dominante sobre el resto de los sectores sociales. Esto se puede vincular de distintas maneras con la fuerza relativa de la clase obrera y sectores populares. Por un lado, las disputas entre los de arriba expresan la relativa fuerza popular;aunque, también, pueden ser parte de esta fuerza relativa en cuanto actúan como estructuras de oportunidades políticas que aminoran la capacidad represiva y consensual del Estado, y por tanto incrementan la capacidad de movilización de los trabajadores, como en la transición política democrática de Argentina (1983). La crisis del régimen "cuasi-democrático" del PRI, que se abre con la crisis económica de 1982, no afectó sustancialmente el control sobre el movimiento obrero.

Burawoy (1983) señalaba que los aparatos políticos en la producción limitaban el poder discrecional de los patronos en los lugares de trabajo. Esto se lograba mediante leyes de seguridad en el contrato de trabajo, de protección sindical, etc. De los estudios sobre México podríamos sostener la importancia, pero circunscripta a las grandes empresas, en particular las estatales (petróleo, electricidad, ferrocarriles). En este mismo esquema, puede considerarse a los docentes. Sin embargo, en la práctica el uso de la regulación se acopló a una estrategia de control, más que de movilización autónoma. La regulación instituyó un movimiento obrero fragmentado con poca autonomía política.

En la legislación mexicana la compleja distinción de tipos de sindicatos, con mayoría de los sindicatos de base de empresa en la industria, debilitaron el poder de negociación institucional del movimiento obrero. Aunque la legislación garantiza la democracia sindical, en la práctica esta es casi inexistente, ya que no se garantiza realmente. La legislación se ha usado para fines represivos, antes que como garantía. Una legislación menos coercitiva en Argentina, pero igualmente designada como "corporativista", no pudo garantizar en la práctica la sumisión del movimiento obrero al estado a largo del siglo XX y lo que va del XXI.

Foweraker y Landman (1997) realizaron una medición de los derechos formales y los "derechos en la práctica”. Su medición arroja una correlación negativa entre ambos en México, que contrasta con las correlaciones positivas en Brasil, Chile o España. Ellos proponen como explicación que cuando los derechos formales se expanden, en la práctica no se realizan, e incluso se incrementan la represión y falta de garantías, como respuesta a la movilización popular. La movilización popular se vería incentivada por la promulgación de garantías de derecho, pero este mismo incremento de las luchas es respondido con represión, que anula las garantías formales en la práctica (, pp. 111 ss.). Esta medición sugiere que los recursos institucionales de 
los actores que inciden en las relaciones de fuerza deben mirarse en la práctica institucional, antes que en la reglamentación formal. En relación con el debate sobre recursos de poder, el análisis de los recursos de poder institucional debe contextualizarse no solo para indicar capacidades para los movimientos obreros, sino también para los grupos y clases que detentan el poder político y social. En este sentido, la legislación laboral sindical puede convertirse en un "arma de doble filo", como señala recientemente Runciman (2019) a propósito del corporativismo en Sudáfrica.

A pesar de la llamativa expansión del empleo maquilador, desde los años 1970 y 1980, este régimen ha enfrentado poca resistencia obrera y no ha registrado significativa conflictividad abierta. Esta industria ha garantizado no solo la apertura e inserción económica en los mercados mundiales (básicamente, como extensión del norteamericano), sino un régimen de control sobre la nueva clase trabajadora. Las investigaciones destacan la contratación de mujeres jóvenes y solteras como parte de una muy alta y llamativa rotación de los empleados, con una corta antigüedad en la empresa (no mayor de 3 años) (Carrillo, 1992 y 2014; Fernández-Kelly, 1983; Wilson, 2002 y 2003). Esta política de contratación busca movilizar económicamente la dominación patriarcal presente en la sociedad y en las unidades familiares. Esta cultura patriarcal asigna roles productivos subordinados en la familia, que se extienden, sin modificarse, con el ingreso de las mujeres en las nuevas maquilas. Aunque las obreras comienzan a percibir ingresos propios, mayormente han vivido en unidades familiares junto con sus padres, y luego con sus maridos, continuando con su posición subordinada. La reproducción de este tipo de relaciones familiares ayuda a que las trabajadoras se definan como mujeres y madres, antes que como obreras. En coherencia con esto, el empleo fabril es visto como un pasaje corto en un proyecto de vida basado en el papel de la feminidad subordinada en el hogar, lo cual se condice con los datos respecto de la duración en las maquilas. La importancia estratégica de este "régimen de género" de control laboral, en el período neoliberal, reside en que la economía mexicana ha girado en torno a las IME, y esta, durante el primer período, ha contratado mayormente este grupo de mujeres, aunque luego se ha incrementado el ingreso de varones.

\section{COMPARACIÓN DE LA MOVILIZACIÓN DE LAS CLASES TRABAJADORAS EN AMBOS PAÍSES}

Si miramos los indicadores de la movilización de los trabajadores, podemos apoyar la hipótesis de una desmovilización de los trabajadores mexicanos, en comparación con los datos para Argentina. Este apartado se subdivide en los siguientes indicadores cuantitativos: de afiliación sindical, negociación colectiva, conflictividad laboral, representación política. Por último, haremos una referencia a los estudios sobre nuevas formas de movilización. Esta referencia será importante para matizar la hipótesis de la desmovilización, sosteniendo que en México se evidencian formas de movilización alternativas al sindicalismo.

Afiliaciónsindical. En México la afiliación sindical había caído del 30\% (1990) al 20\% (2000) de los asalariados no agrícolas, mientras que en Argentina había pasado del 40\% (1990) al 42\% (2000). La afiliación sindical en la manufactura en México era del 30\% en 1990 y 20\% en 2000; en Argentina, 70\% en 1990 y $66 \%$ en 2000 (Marshall, 2006, p. 23). ${ }^{10}$ En México, la afiliación se ha concentrado en el sector público y en la educación. Más de la mitad del total de afiliados corresponde al sector público y un cuarto del total se ubica en el sindicato docente (Sindicato Nacional de Trabajadores de la Educación, SNTE) (Zepeda Martínez, 2009, p. 76). En este sector la afiliación es cuasi compulsiva, ya que el acceso a los cargos es negociado por los sindicatos, aunque esta atribución ha sido debilitada en los 2000 por las nuevas reformas que introducen el pluralismo sindical. Este dato es significativo respecto del poder de negociación estructural de la organización, el cual se habría debilitado en México en los sectores con posiciones de poder económico (grandes empresas productivas, maquilas). La base política del sindicalismo mexicano se ha trasladado al sindicato de maestros (SNTE). 
Negociación colectiva. Solo un $10 \%$ de la fuerza laboral estaría cubierta por la negociación colectiva en México, contra 60\% en Argentina (Hayter y Stoevska, 2011). Esto se agrava por la existencia de los denominados "sindicatos de membrete" inexistentes, que firman "convenios" previamente a la instalación de las maquilas, en nombre de empleados que no han sido contratados. El contenido de estos convenios generalmente es favorable a las patronales. En el caso argentino, el desarrollo de la negociación colectiva, junto con la fuerza sindical, luego de la crisis de 1998-2002, habría tenido un impacto favorable en los salarios. No obstante, esto no es contradictorio con la continuidad de un régimen fabril de "legalidad industrial flexible", esto es, la negociación en los lugares de trabajo con pautas tendientes a la flexibilidad (Soul, 2012; Marticorena, 2014). A diferencia de la flexibilización como tal, aquí las normas flexibles se incorporan mediante acuerdos colectivos con los sindicatos.

Por otro lado, la institución del salario mínimo ha sido históricamente importante en México, y en Argentina durante la gestión kirchnerista (ver Payo Esper, 2015). Empero, en México la misma se ha dedicado a limitar el incremento del valor del salario mínimo, desde las políticas neoliberales (Fairris, Popli y Zepeda 2008). Podemos definir el poder sindical como la capacidad de imponer los intereses de los trabajadores. Para que la movilización exprese poder, entonces, debería incorporarse la relación entre esta y el modo en que afectan los intereses de clase. En este sentido, los estudios sobre la relación entre sindicalización y salarios muestran que las diferencias salariales entre sectores o individuos se explican, en alguna medida, por la organización colectiva de los trabajadores (fuerza sindical) (Barrera, 2017). Podríamos conjeturar que las diferentes fuerzas sindicales nacionales explican parcialmente las variaciones salariales. Hay estudios para cada caso nacional que han observado esta hipótesis (Barrera, 2017, para Argentina; Fairris, 2003, para México). Se ha planteado a nivel internacional que la desigualdad entre los salarios se relaciona con la fuerza salarial (Visser y Checchi, 2011). Una mayor desigualdad indicará una influencia menor de los sindicatos en la definición nacional de los salarios. Esto es congruente con los datos de desigualdad salarial:28.8 puntos Gini para Argentina, y 41.1 para México (ILO, 2018). De cualquier modo, esta referencia señala una línea de investigación más, sugerida por este ensayo, que hace a los efectos de la fuerza sindical sobre los salarios.

Conflictividad laboral. La comparación de la actividad huelguística es muy contrastante. Van der velden, Dribbush y Lyddon (2007, p. 23) construyeron figuras comparadas en 15 países. En Argentina el volumen de las huelgas es de 900 huelguistas cada 1000 trabajadores, contra 4 huelguistas cada 1000 trabajadores en México. Hemos señalado también la inexistencia de huelgas generales en este país, mientras que en Argentina las mismas son reiteradas. Con el debilitamiento del movimiento obrero en los años 1990, hubo una declinación notoria de las huelgas en Argentina en esa década, luego de la implantación efectiva del Plan Cavallo en 1992, y de derrotas estratégicas por las privatizaciones. En este contexto, la paralización general del trabajo ha descansado más en la capacidad sindical en los sectores estratégicos, tales como los transportes de personas y mercancías, así como la industria. No obstante, la actividad huelguista por ramas y empresas ha crecido notablemente, luego de la recuperación del mercado de trabajo y la economía desde 2003.

Representación política. En ambos países, durante el período neoliberal, se ha observado la declinación de la participación de los representantes sindicales en los poderes de decisión política estatal. El indicador más usado es la cantidad de parlamentarios. Así, el porcentaje de diputados "obreros" más diputados "cetemistas" (pertenecientes a la Confederación de Trabajadores Mexicanos) sobre el total de diputados habría pasado del 33\% en el período 1979-1982 al 8\% en el período 2006-2009 (Zepeda Martínez, 2009, p. 62). Los diputados cetemistas, a su vez, han perdido más participación frente a nuevas agrupaciones intersindicales, fundamentalmente la encabezada por el SNTE. Una tendencia muy similar se experimentó en Argentina, por lo que se habla de la desindicalización del partido peronista (Levitsky, 2005).

Nuevas formas de movilización. La debilidad de poder de los trabajadores sindicalizados puede dar lugar a la expresión de luchas populares por fuera del movimiento obrero, como en México sucede con movimientos campesinos o indígenas. Desde una concepción ampliada de la clase trabajadora, ciertos movimientos rurales o sociales podrían formar parte de las protestas laborales (Silver, 2005). Este tipo de movimientos son 
visibles en México y en Argentina. La ampliación de la observación a la protesta laboral no-sindical se deja de lado en los estudios institucionales, debido a que se concentran en los sistemas formales de relaciones laborales y por tanto en la fracción más protegida de la clase obrera. En Argentina, con el crecimiento de la desocupación a fines de la década del 90, se crearon numerosos movimientos de "trabajadores desocupados", los cuales incrementaron su coordinación nacional, y con esta la coordinación de su movilización en los años más duros de la crisis, 2001-2003. Con la recuperación económica posterior, los movimientos continuaron actuando. Hacia 2010, una gran parte de estos ha creado la CTEP (Confederación de Trabajadores de la Economía Popular), en la que incluyen anteriores movimientos de desocupados, junto con cooperativas de trabajo (Santella, 2018). Estos movimientos ejemplifican el uso de recursos societales que los grupos de trabajadores de los sectores informales evidencian en otros casos nacionales, como mencionamos más arriba. Los movimientos de trabajadores desocupados desarrollaron una estrategia compleja que incluye la organización territorialmente basada, con alianzas institucionales y discursos identitarios con base en la dignidad del trabajo.

En México, el neozapatismo (EZLN), que adquiere protagonismo público desde el levantamiento de Chiapas de 1994, organiza a trabajadores rurales semiproletarizados, agrupados con base a la identidad indígena. Asimismo, la prolongada confrontación en Oaxaca en 2006, con base a una huelga docente dirigida por el SNTE local 22 (de aquel Estado), articuló cientos de movimientos sociales. Estos son dos ejemplos representativos de la movilización social en México, en la cual los movimientos campesinos han tenido un protagonismo generalmente mayor que los movimientos sindicales.

En otro lugar hemos realizado una exploración de las formas de protesta social en Argentina y México entre los años 2000 y 2012 (Montes de Oca, 2019), que viene a sostener esta hipótesis sobre las diferencias en las formas de acción colectiva. Analizando cuantitativamente los eventos de protesta en tres años tomados como muestras (2000, 2006 y 2012 primer cuatrimestre) en ambos países, los datos muestran que los trabajadores del sector formal protagonizan las protestas en mayor medida en ambos países (34\% de los eventos). ${ }^{11}$ Sin embargo, es en el grupo de los diferentes sectores vinculados a la sobrepoblación relativa donde aparecen tajantes diferencias. Podemos tomar a los trabajadores desocupados, informales, pero también a los campesinos e indígenas como referencias a actores que componen identidades colectivas relacionadas con las formas de la sobrepoblación relativa. Estos grupos representan el 15\% de las protestas en ambos países. En Argentina se componen de acciones colectivas de desocupados, trabajadores informales y trabajadores pobres, mientras que en México se compone casi exclusivamente de campesinos e indígenas. De este estudio, por tanto, se destaca la ausencia de movimientos de desocupados y trabajadores informales en México, si miramos las acciones colectivas públicas más relevantes a nivel nacional. En contraste, en Argentina son poco significativas en términos cuantitativos las acciones colectivas campesinas e indígenas.

\section{CONCLUSIONES}

En este ensayo nos hemos propuesto contribuir, por un lado, a la explicación de las diferencias en las trayectorias de la movilización y desmovilización en Argentina y México desde los años 1980. De este modo nos interesa contribuir en la línea de investigación sobre los recursos de poder. Hemos bosquejado un argumento para testearse en la investigación ulterior sobre las diferencias en los recursos de poder en el movimiento obrero de ambos países. Dos variaciones explicarían un grado significativo de desmovilización del movimiento obrero mexicano, en comparación con el argentino;porun lado, debido a la historia de su proletarización, en México el capitalismo se beneficia de una significativa reserva de trabajo basada en una sobrepoblación relativa anclada en la estructura agraria. En el caso argentino, desde los años 1970, la desindustrialización ha expulsado una considerable parte de la mano de obra industrial, que ha engrosado los sectores informales (trabajadores por cuenta propia, sectores menos productivos) y la desocupación y 
subocupación. Esta sobrepoblación relativa es resultado de la expulsión del sector industrial, así como en México proviene de las formas "latentes" de la misma (campesinado). Esto configura experiencias de clase distintas, con posibles impactos en los recursos de poder (conciencia y organización de clase).

Esta realidad se conecta con los procesos políticos de movilización sindical. Durante el siglo XX la revolución mexicana ha incorporado y controlado la estructura sindical sin experimentarse una crisis importante. En contraste, en el caso argentino, la fuerza relativa del movimiento obrero, así como las crisis periódicas del régimen hegemónico, han permitido la continuidad de un sindicalismo comparativamente autónomo. Esta fuerza relativa configura su poder asociativo, sobre el cual ha movilizado contra las políticas neoliberales desde los años 1980. Esta movilización ha sido muy débil en el caso mexicano, si nos detenemos en los indicadores de la actividad huelguística, de la afiliación, y de la cobertura de la negociación colectiva (a pesar de lo que indicaba la normativa formal del régimen laboral). Sobre la base de la organización sindical, el movimiento obrero ha podido mantener una estrategia de aprovechamiento de sus posiciones estructurales, para movilizarse autónomamente en huelgas generales y huelgas sectoriales, como repertorio clásico de su acción colectiva. Este tipo de acción colectiva ha estado ausente en el movimiento obrero mexicano, quitándole capacidad de resistencia frente a la ofensiva neoliberal. La desmovilización sindical en México, el control del régimen hegemónico, y la reserva de trabajo, han sido aprovechas por los capitalistas de otros países para invertir en la IME, transformando la realidad productiva de ese país, y profundizando la debilidad de la organización de su clase trabajadora. Han aprovechado asimismo elrégimen patriarcal en la familia, diseñando una política de contratación que reproduce la subordinación de la fuerza de trabajo femenina.

Sobre la base de este argumento, nos interesa contribuir a los debates sobre los recursos de poder, marcando algunos comentarios sobre sus principales autores. Por un lado, al ampliar la observación histórica de las relaciones de poder en países periféricos (con presencia de amplios sectores informales o de sobrepoblación relativa), introducimos variables no tenidas en cuenta por Eric Olin Wright. Pero también al explorar más en los regímenes hegemónicos de estos países, damos cuenta de mecanismos que pueden ayudar a explicar los resultados de desmovilización frente a las nuevas olas de proletarización, como en México, que no habían sido tenidos en cuenta en el trabajo maestro de Beverly Silver. Ella afirmaba que:

Los principales fabricantes de automóviles del mundo han seleccionado al menos dos nuevos lugares de bajos salarios para acometer una rápida expansión, el norte de México y China. Si las dinámicas del pasado sirven como guía para las tendencias del futuro, tenemos buenas razones para esperar el surgimiento de fuertes movimientos obreros independientes en México y China durante la próxima década (Silver, 2005, p. 81).

Partiendo de la ausencia de estos movimientos obreros, en este artículo hemos buscado articular algunas sugerencias explicativas. El nivel de análisis nacional y regional puede modificar las tendencias esperadas en los ciclos globales de inversión y movilidad sectorial de capital. Las hipótesis de Silver no tienen en cuenta los datos propios de las unidades locales de análisis, que bien pueden contradecir las dinámicas globales. Pero este análisis no se trata solo de niveles escalares sino también de lo que propone el debate de los recursos de poder, esto es, de la combinación entre distintas relaciones de poder estructural, asociativa, societal e institucional. En este trabajo, tomamos estas dimensiones de modo relacional, no solo desde el punto de vista de la estrategia de los trabajadores sino también como formas de poder que ayudan a explicarla desmovilización.

\section{Agradecimientos}

A los miembros del proyecto de investigación sobre movilización sindical en Argentina, Brasil y México (PICT 2016-0780), Julia Soul, Julián Gindin, Luis Castillo, Diego B. Páez, Inés Montarcé, Facundo Barrera y Ricardo Donaire por los intercambios previos y a los evaluadores anónimos. 


\section{REFERENCIAS}

A.A.V.V. (2006). Historias de la maquila. Desacatos, 21, 162-170.

Adelman, J. (1992). Essays in Argentine Labour History1870-1930. London: Palgrave McMillian.

Albornoz Mendoza, L. y Ortiz Pech, R. (2000). La industria maquiladora como sostén de las comunidades rurales en Yucatán. Comercio Exterior, 20(5), 448-452.

Ansaldi, W. (comp.) (1993). Conflictos obrero rurales pampeanos (1900-1937). Buenos Aires: CEAL.

Barrera, F. (2017). Desigualdad salarial sectorial en la Argentina (2003-2012): entre las caracteristicas productivas de los capitales y la acción sindical (Tesis de doctorado inédita). Universidad de Buenos Aires, Buenos Aires.

Bartra, A. (1985). Los herederos de Zapata: movimientos campesinos posrevolucionarios en México, 1920-1980. México: Era.

Bensusán, G. y Cook, M. L. (2015). State-corporatist legacies and divergent paths: Argentina y México. En T. Caraway, M. L. Cook y S. Crowley (Ed.), Working through the past. Labor and authoritarian legacies in comparative perspective (pp 142-163). Ithaca: ILR Press.

Bensusán, G. (2016). Organizing workers in Argentina, Brazil, Chile and Mexico: the authoritarian-corporatist legacy and old institutional designs in a new context. Theoretical inquiries, 16(131), 131-163.

Bergquist, Ch. (1988). Los trabajadores en la historia latinoamericana. Estudios comparativos de Chile, Argentina, Venezuela y Chile. Bogotá: Siglo XXI.

Bhattacharya, R. y Sanyal, K. (2009). Beyond the factory: globalisation, informalisation of production and the new location of labour. Economic and Political Weekly, 44(22), 35-44.

Burawoy, M. (1983). Between labor process and the state: the changing face of factory regimes under advanced capitalism. AmericanSociological Review, 48(5), 587-605.

Carrillo, J. y Hernández, A., (1985). Mujeres fronterizas en la industria maquiladora. México: SEP-Centro de Estudios Fronterizos del Norte de México.

Carrillo, J. (1992). Mujeres en la industria automotriz. México: El Colegio de la Frontera Norte.

Carrillo, J. (1994). Mujeres en la industria maquiladora de autopartes. En V. Salles y E. McPahil (Coord.), Nuevos textos y renovados pretextos (pp. 177-217). México: El Colegio de México.

Carrillo, J. (2014). ¿De qué maquila me hablas? Reflexiones sobre las complejidades de la industria maquiladora en México. Frontera Norte, 26(3), 75-98.

Córdova, A. (1976). La politica de masas del cardenismo. México: Era.

Collier, R. B. y Collier, D. (1979). Inducements versus constrains: disaggregating corporatism. The American Political Science Review, 73(4), 967-986.

Collier, R. B. y Collier, D. (1991). Shaping the political arena. Critical junctures, the labor movement, and regime dynamics in Latin America. Princeton: Princeton University Press.

Cook, M. L. (2007). The politics of labor reform in Latin America. Between flexibility and rights. Pennsilvania: Penn State University Press.

Denning, M. (2011).La vida sin salario. New Left Review, 66, 77-94.

Díaz González, E. (2009). Mercado de trabajo e industria maquiladora en Sonora y la frontera norte. Región y Sociedad, $X X I, 44,43-70$.

Donaire, R. (2018). Las modalidades de la superpoblación: Argentina en el contexto regional latinoamericano a comienzos del siglo XXI. Buenos Aires: manuscrito inédito.

Dorocki, S. y Brzegowy, P. (2014). The maquiladora industry impact on the social and economic situation in Mexico in the era of globalization. En M. Wojtowicz, y A. Winiarczyk-Razniak (Ed.), Environmental and socio-economic transformation in developing areas as the effect of globalization (pp. 93-110). Krakow: Wydawnictwo Naukowe UP. 
Elbert, R. (2018). Informality, class structure and class identity in contemporary Argentina. Latin American Perspectives, 45(1), 47-62.

Kelly, J. (1998). Rethinking industrial relations. London: LSE.

Guzmán Ferrer, M. L. (1975). Coyuntura actual de la agricultura mexicana. Comercio Exterior, 25(5), 572-584.

Fairris, D. (2003). Unions and wage inequality in Mexico. ILR Review, 56(3), 481-497.

Fairris, D., Popli, G. y Zepeda, E. (2008). Minimum wages and wage structure in Mexico. Review of Social Economy, 66(2), 181-208.

Fernández-Kelly, M. P. (1983) For we are sold, I and my people. Women and industry in Mexico's frontier. Albany: State University of New York Press.

Foweraker, J. y Landman, T. (1997). Citizenship rights and social movements. A comparative and statistical analysis. Oxford: Oxford University Press.

Franzosi, R.(1995). The puzzle of strikes. Cambridge: Cambridge University Press.

Frenkel, R. y Ros, J. (2004). Desempleo, políticas macroeconómicas y flexibilidad del mercado laboral. Argentina y México en los noventa. Desarrollo Económico, 44(173), 33-56.

Gilly, A. (1997). Chiapas: la razón ardiente. México: Era.

Hayter, S. y Stoevska, V. (2011). Social dialogue indicators. International statistical inquiry 2008-2009. Geneva: International Labour Office.

Hesket, C. (2010). From passive revolution to silent revolution: class forces and the production of state, space and scale in modern Mexico. Capital and Class, 34(3), 383-407.

International Labor Organization (2018), Global Wage Report 2018/19. Genova: ILO.

Iñigo Carrera, J. (2007). La formación económica de la sociedad argentina. Buenos Aires: Imago Mundi.

Kalm, S. (2001). Emancipation or exploitation? A study of women workers in Mexico's maquiladora industry. Statsevetenskaplig Tidskrift, 103(3), 224-258.

Kelly, J. (1998). Rethinking industrial relations. London: LSE.

Knight, A. (1992). The peculiarities of the Mexican history: Mexico compared to Latin America, 1821-1992. Journal of Latin American Studies, 24, 99-144.

Korpi, W. y Shalev, M. (1979). Strikes, industrial relations and class conflict in capitalist societies. The British Journal of Sociology, 30(2), 164-187.

Korzeniewicz, R. P. (1993). Labor unrest in Argentina, 1930-1943. Latin American Research Review, 28(1), 7-40.

Levitsky, S.(2005). La transformación del justicialismo. Buenos Aires: Siglo XXI.

Marshall, A. (2006). Efectos de las regulaciones del trabajo sobre la afiliación sindical: estudio comparativo de Argentina, Chile y México. [Monografía]. Cuadernos del IDES, 8.

Marticorena, C. (2014). Trabajo y negociación colectiva. Buenos Aires: Imago Mundi.

McGuire, J. (1997). Peronism without Perón. Stanford: Stanford University Press.

Middlebrook, K. (1989). The sound of silence. Organised labour's response to economic crisis in Mexico.Journal of Latin American Studies, 21(2), 195-220.

Mikkelsen, F. (1996). Working-class formation in Europe: in search of a synthesis. [Monografía]. International Institute of Social History.

Montes de Oca, I.(2019). La movilización de los trabajadores pobres e informales en Argentina y México. Ponencia presentada en las XXVIII Jornadas de Sociología, Buenos Aires, Universidad de Buenos Aires.

Nielson, D. y Stubbs, T. (2011). Relative surplus population and uneven development in the neoliberal era: theory and empirical application. Capital and Class, 8(3), 435-453.

Nun, J. (1969). Superpoblación relativa, ejército industrial de reserva y masa marginal. Revista Latinoamericana de Sociología, 5(2), 178-236. 
Payo Esper, M. (2015). Algunas consideraciones en torno al salario mínimo y a la dinámica de la CGT en el Consejo del salario en la post-convertibilidad. Estudios del trabajo, 24, 95-108.

Pianetto, O. (1984). Mercado de trabajo y acción sindical en la Argentina, 1890-1922. Desarrollo Económico, 24(94), 297-307.

Portantiero, J. C. (1983). Los usos de Gramsci. México: Folios.

Portes, A. y Hoffman, K. (2003). La estructura de clases en América Latina: composición y cambios durante la era neoliberal. Desarrollo Económico, 43 (171), 355- 387.

Ramírez, J. C. (1988). La nueva industrialización en Sonora: el caso de los sectores de alta tecnología. Sonora: El Colegio de Sonora.

Reina, L. (1998). Las rebeliones campesinas en México (1819-1906). México: Siglo XXI.

Rosati, G. (2015). Problemas en torno das funcoes da popolacao sobrante no capitalismo dependente: umexercicio da comparacao entre as formaciones sociales argentina e brasileira (1980-2009). En D. De Souza (Org.), Desemprego e protestos sociais no Brasil (pp. 93-110). Sao Paulo: Editora FAP-UNIFESP.

Runciman, C. (2019). The double-edged sword of institutional power: COSATU, Neo-liberalisation and the right to strike. Global Labour Journal, 10(2), 142-159.

Santella, A. (2017). Labor Conflict and Capitalist Hegemony. The auto-industry in Argentina 1990-2007. Chicago: Haymarket.

Santella, A. (2018). Los docentes, trabajadores informales y mujeres: ¿nuevos sectores combativos de la clase trabajadora en Argentina? En P. Pérez y E. López (Comp.), ¿Un nuevo ciclo regresivo en la Argentina? Mundo del trabajo, conflictos laborales y crisis de hegemonia (pp. 233-254). La Plata: FaHCE.

Schmlaz, S., Ludwig, C. y Webster, E. (2018). The power resources approach: developments and challenges. Global Labor Journal, 9(2), 113-134.

Schmalz, S., Ludwig, C. y Webster, E. (2019).Power resources and global capitalism. Global Labour Journal, 10(1), $84-91$.

Silver, B. (2005). Fuerzas del trabajo. Madrid: Akal.

Soul, J. (2012). Las relaciones capital-trabajo en la industria siderúrgica. ¿Expresión de una nueva legalidad industrial? Estudios del trabajo, 42-43, 81-112.

Steinberg, M. W. (1999). Fighting words. Working class formation, collective action and discourse in Early nineteenthcentury England. Ithaca: Cornell University Press.

Svampa, M. (2016). Debates latinoamericanos. Buenos Aires: Edhasa.

Tilly, Ch. (1979). Proletarianization: theory and research. [Monografía]. CRSO Working Paper, 202.

Trevizo, D. (2011). Rural protest and the making of democracy in Mexico, 1968-2000. Pennsylvania: Pennsylvania State University Press.

Van der Velden, S., Dribbush, H. y Lyddon, D. (2007). Strikes around the world, 1968-2005. Amsterdam: Aksant.

Visser, J y Checchi, D. (2011).Inequality and labor market. En B. Nolan, W. Salverda and T. Smeeding (Ed.),The Oxford Handbook of Economic Inequality,

Wada, T. (2004). Event analysis of claim making in Mexico: how are social protests transformed into political protests? Mobilization, 9(3), 241-257.

Wilson, T. D. (2002). The masculinization of the Mexican maquiladoras. Review of Radical Political Economics, 34, 3-17.

Wilson, T. D. (2003). Forms of male domination and female subordination: homeworkers versus Maquiladora workers in Mexico. Review of Radical Political Economics, 35(1), 56-72.

Womack, J. Jr. (2007). Posición estratégica y fuerza obrera. Hacia una nueva historia de los movimientos obreros. México: Fondo de Cultura Económica.

Wright, E. O. (2000). Working-class power, capitalist-class interests, and class compromise. American Journal of Sociology, 105(4), 957-1002. 
Zepeda Martínez, R. (2009). Disminución de la tasa de trabajadores sindicalizados en México durante el período neoliberal. Sociedad y politica, 10, 57-81.

\section{Notas}

1 Korpi y Shalev (1979) es otro antecedente clave.

2 Esto representa una posición estratégica en los términos de Womack (2007). Había sido observado por Burawoy cuando sostenía que "a pesar del alto desempleo, los trabajadores aprovecharon la interconexión del proceso de trabajo y la interdependencia de las ramas para paralizar la industria de masa” (1983, p. 598). Bergquist (1988) usa este concepto como clave comparativa del movimiento obrero latinoamericano.

3 El concepto de sobrepoblación relativa es tomado de Marx, capítulo 23 de El capital y fragmentos de los Grundisse. Denning (2011) reúne estos fragmentos en su estudio de los movimientos sociales informales de la India. Sintéticamente, podemos definir sobrepoblación relativa en el capitalismo a la parte de la población que no se incorpora al sector productivo de capital, empleándose en los sectores capitalistas menos productivos o actividades en relaciones de explotación no directamente capitalistas. Este concepto ha sido revitalizado por la tesis de la masa marginal de Nun (1969) (para su debate ver Svampa, 2016, pp. 215 y ss.). Usamos sobrepoblación relativa y no masa marginal debido a los supuestos de esta última. En particular, esta tesis presupone una rígida separación entre el sector productivo e improductivo (informal) que entendemos no se ajusta a la experiencia, tal como indicaremos más abajo.

4 Véase Iñigo Carrera (2007) para una serie de largo plazo de los salarios rurales e industriales en Argentina, Inglaterra y Estados Unidos. Para la conflictividad laboral rural, ver Adelman (1992), Korzeniewicz (1993) y Ansaldi (1993).

5 Para Argentina véase Elbert (2018). Para México, Frenkel y Ros (2004), Wilson (2002).

6 El empleo en las maquiladoras creció de 3.000 trabajadores en 1965 a 2.000.247 en 2012, empleados en 12 maquiladoras en el primer año de referencia, y en 5.005 en el segundo (Dorocki y Brzegowy, 2014, p. 102).

7 Carrillo y Hernández (1985, p. 117) sostienen que, en 1978, más de la mitad de la fuerza de trabajo de las IME de Ciudad Juárez era de origen rural, aunque esto habría cambiado mucho hacia 1988 reduciéndose al 8\% (Carrillo, 1994, p. 205). Para Ramírez (1988), en las maquiladoras de Sonora en 1985, un tercio de los operarios son migrantes rurales. Kalm (2003) sostiene que hay una presencia significativa en 2000 de la inmigración rural en Tijuana. Albornoz Mendoza y Ortiz Pech (2000), por su parte, analizan la destacada participación de la comunidad rural en Yucatán en las maquilas cercanas, que se convirtieron en una alternativa de ingresos frente a la crisis agrícola. Los obreros maquiladores siguen viviendo en comunidades rurales, de las que fueron trabajadores del campo. Las historias de vida ilustran tanto la riqueza de la movilidad de los trabajadores entre sectores de actividad y categorías ocupacionales, así como la composición migratoria. Agustina García Reyes tenía 42 años en 2006. Sus padres trabajan en el campo, en un pueblo donde ella nació (Puebla). Comenzó siendo costurera a los 20 años en su pueblo Ocotepec, luego empleada doméstica en la Ciudad de México y posteriormente en la industria maquiladora en Matamoros. Eva Bailón de la Cruz tenía 30 años en 2006, nacida en San Marcos, Guerrero. "Nos criamos campesinos". Se mudó a los 18 a Los Cabos, Baja California, trabajando de mesera. Luego fue a Tijuana, con hijos, comenzando a trabajar en una fábrica de canasta con una paga muy baja y por último en Sanyo, donde pagaban 50 pesos más semanalmente. Margarita, de Matamoros, comenzó en una empresa de artesanías, recibiendo el salario mínimo para luego incorporarse en CTS donde "hacían switch, radios, bocinas" (testimonios en revista Desacatos, 21, 2006, pp. 162-170).

8 En el mismo sentido, Córdova (1976), Collier y Collier (1991), Knight (1992), Portantiero (1983) y Trevizo (2011). Para Hesket (2010) este modo hegemónico expresa una forma de "revolución pasiva".

9 Como señala Wada (2004), “en México hasta la crisis económica de 1982, la relación entre el Estado y la población se caracterizaba por los acuerdos institucionales y los entendimientos culturales duraderos que priorizaban los derechos sociales y colectivos" (p. 241).

10 Zepeda Martínez (2009) da crédito a una tasa del 10\% de afiliación en México, menor al 20\% que registra Marshall.

11 Estos datos fueron elaborados a partir de la base de conflictos sociales del Proyecto PICT "Relaciones laborales y movilización sindical en Argentina, Brasil y México". No hemos analizado aún el grupo de los trabajadores formales que tienen en México y Argentina, como se ve, un peso similar en relación al conjunto de eventos de conflicto social. La hipótesis que se sigue del relato de este artículo es que en México las protestas de los trabajadores formales son representadas mayormente por docentes con marchas como forma de acción, mientras que en Argentina se distribuye entre los sectores industriales, de transporte y sector público, sea en huelgas o marchas. 